\title{
Reduced oxidase activity in the caeruloplasmin of two families with Wilson's disease
}

\author{
J. L. GOLLAN ${ }^{1}$, J. STOCKS, T. L. DORMANDY, AND SHEILA SHERLOCK \\ From the Department of Medicine, Royal Free Hospital, Pond Street, Hampstead, London NW3 and \\ the Department of Chemical Pathology, Whittington Hospital, Archway, London N19
}

SUMMARY Caeruloplasmin has been determined immunologically and by copper oxidase activity in 25 normal subjects, 20 patients with Wilson's disease, and 80 patients with chronic liver disease. Repeated estimation in four patients with Wilson's disease and two heterozygous mothers from two families revealed a consistent reduction in the copper oxidase activity of caeruloplasmin (12-32 units copper oxidase activity/mg caeruloplasmin) relative to the values obtained in normal subjects, patients with chronic liver disease, and other Wilson's disease patients (mean 65-79 units/mg). It is suggested that the functional abnormality in caeruloplasmin observed in these two families is an inherited variant, which does not appear to be due to the presence of a serum inhibitor of copper oxidase.

The biochemical diagnosis of Wilson's disease depends on a reduced level of serum caeruloplasmin (less than $20 \mathrm{mg} / \mathrm{dl}$ ) and an elevated hepatic copper concentration (greater than $250 \mu \mathrm{g} / \mathrm{g}$ dry tissue) (Sternlieb and Scheinberg, 1968). A few patients possess normal serum concentrations of caeruloplasmin (Bearn, 1953; Scheinberg and Sternlieb, 1963) but the levels usually fall during the course of D-penicillamine therapy.

The physiological role of caeruloplasmin is thought to be that of a ferroxidase. However, it can oxidise a wide variety of substrates, and the ability to catalyse the oxidation of aryldiamines has been widely employed in colorimetric assays for caeruloplasmin. Recently, due to the availability of commercial reagents, the measurement of caeruloplasmin immunochemically has gained acceptance on the assumption that immunoreactive caeruloplasmin is closely correlated with serum copper oxidase activity. While this may be true of most groups of subjects, in this study we report four patients with Wilson's disease and two heterozygous carriers of the 'Wilson's disease gene' from two families, in whom a marked reduction in the copper oxidase activity of caeruloplasmin was observed relative to the values obtained in normal subjects, other patients with Wilson's disease, and patients with a variety of chronic liver diseases.

'Present address: $1120 \mathrm{HSW}$ Department of Medicine, University of California, San Francisco, Ca 94143, USA

Received for publication 2 June 1976

\section{Methods}

Copper oxidase activity was determined by a method modified from that of Curzon and Vallet (1960). Serum $(100 \mu \mathrm{l})$ was incubated at $37^{\circ} \mathrm{C}$ in $5.1 \mathrm{ml}$ $0.43 \mathrm{~mol} / \mathrm{l}$ sodium acetate buffer, $\mathrm{pH} 5 \cdot 5$, containing $20 \mathrm{mmol} / \mathrm{l} \mathrm{N}, \mathrm{N}$-dimethyl-p-phenylenediamine sulphate and the increase in absorbance was recorded at one-minute intervals. The reaction rate was calculated from the average over 10 minutes while the reaction was linear, after allowing for the initial lag period of 1-2 minutes. In sera showing low copper oxidase activity measurement was continued for up to 30 minutes. The results are expressed as units $/ \mathrm{ml}$ serum, defining 1 unit as equivalent to an increase in absorbance at $530 \mathrm{~nm} / \mathrm{min}$ of $0 \cdot 01$. Caeruloplasmin was measured immunochemically by single radial immunodiffusion using $\mathbf{M}$ Partigen immunodiffusion plates and standards supplied by Hoechst Pharmaceuticals.

\section{Patient studies and results}

In 25 normal subjects (14 males and 11 females, aged 16-52 years) there was a positive correlation between the caeruloplasmin and copper oxidase activity. Mean values for caeruloplasmin were $32 \cdot 6$ $\pm 7.7 \mathrm{mg} / \mathrm{dl}( \pm \mathrm{SD})$, copper oxidase $25.7 \pm 3.9$ units $/ \mathrm{ml}$, and copper oxidase $/ \mathrm{mg}$ caeruloplasmin $79 \pm 19$ units/mg. An abnormally decreased serum 

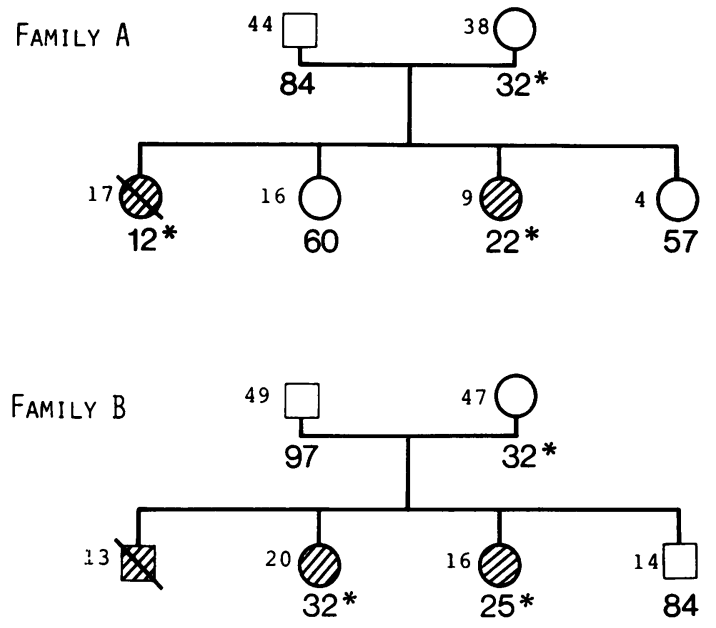

Figure Family pedigrees represented by the symbols $\square$ male, $\bigcirc$ female, $Q$ deceased, with the ages shown beside the symbols. Shaded symbols indicate family members with Wilson's disease. The mean copper oxidase activity/mg caeruloplasmin is shown beneath the symbol and abnormal values have been marked with an asterisk.

oxidase activity relative to the concentration of caeruloplasmin was first encountered in a 17-yearold girl with Wilson's disease (Figure-family A), who died following a gastro-oesophageal haemorrhage in 1973, four weeks after admission to hospital with an active cirrhosis and hepatic failure. The hepatic copper determined in necropsy specimens was greater than $600 \mu \mathrm{g} / \mathrm{g}$ dry tissue. Serum caeruloplasmin and copper oxidase activity were measured on 14 occasions during her stay in hospital and ranged from 19 to $25 \mathrm{mg} / \mathrm{dl}$ and 1.6 to 3.2 units $/ \mathrm{ml}$, respectively. A similar discrepancy in oxidase activity relative to the concentration of caeruloplasmin was evident in the 9-year-old sister (Figure) with asymptomatic Wilson's disease, in whom the serum caeruloplasmin ranged from 13.5 to 21.0 $\mathrm{mg} / \mathrm{dl}(\mathrm{n}=6)$ during the initial 12 months on $\mathrm{D}$ penicillamine therapy, and in the heterozygote mother (caeruloplasmin 21.4 to $36.0 \mathrm{mg} / \mathrm{dl} ; \mathrm{n}=4$ ). All values obtained in the remaining members of the family were normal (caeruloplasmin, 30 to $36 \mathrm{mg} / \mathrm{dl}$ and copper oxidase, 20 to 25 units $/ \mathrm{ml}$ ).

Study of an additional 18 patients with Wilson's disease from 14 families revealed an additional family in whom two sisters with the disease and their mother had a discrepancy between caeruloplasmin and oxidase activity. In this family (Figure-family B), Wilson's disease was diagnosed in a 13-year-old boy shortly before his death from bleeding oesophageal varices in 1968. The sisters, now 20 and 16 years of age, were diagnosed subsequently and have음 both remained asymptomatic on D-penicillamine. Serum caeruloplasmin measured on three occasions $\frac{\text { ? }}{+}$ over 12 months was consistently 11 and $18 \mathrm{mg} / \mathrm{d} I \mathrm{C}$ respectively, and $29 \mathrm{mg} / \mathrm{dl}$ in the heterozygote $\frac{\bar{c}}{.}$ mother. In the father and son, values were normal for $\frac{\bar{s}}{\overline{0}}$ caeruloplasmin (30 and $28 \mathrm{mg} / \mathrm{dl}$ respectively) and $\mathbb{\complement}$ the copper oxidase activity/mg caeruloplasmin (Figure). Serum caeruloplasmin concentrations in $11 \vec{~}$ of the remaining 16 patients with Wilson's disease (aged 14 to 36 years) were less than $5 \mathrm{mg} / \mathrm{dl}$ and $\vec{\omega}$ hence too low for the oxidase activity to be related? accurately to caeruloplasmin. In five patients 30 female, 2 male), serum caeruloplasmin ranged from $\omega_{0}$ 9 to $21 \mathrm{mg} / \mathrm{dl}$ and the copper oxidase activity $/ \mathrm{mg}_{-}^{-}$ caeruloplasmin was similar to that observed in normal subjects. All patients in this latter group had $\vec{\circ}$ histological or biochemical evidence of hepatic in- $?$ volvement and only one had not begun D-penicilla- $\bar{C}$ mine therapy. To determine whether the presence of $\stackrel{2}{=}$ liver disease influenced the oxidase activity of caeruloplasmin, 80 patients with chronic active hepatitis, primary biliary cirrhosis, cryptogenic cirrhosis, or $\vec{\theta}$ alcoholic liver disease were studied. The mean values $V$ for serum caeruloplasmin, $40.5 \pm 12.5 \mathrm{mg} / \mathrm{dl}$, and copper oxidase units/mg caeruloplasmin, $65 \pm 14$, ᄋ were comparable with those in normal subjects.

Dialysis of sera from individuals with low copper. oxidase activity/mg caeruloplasmin for 24 hours against $0 \cdot 15 \mathrm{~mol} / \mathrm{l} \mathrm{NaCl}$ had no significant effect on $\stackrel{\varrho}{\Rightarrow}$ copper oxidase activity under the conditions of the assay. After addition of an equal volume of these sera to normal serum, the copper oxidase activity? was equal to the average of the two activities within the limits $\pm 5 \%$. These results indicate that there? was no dialysable non-competitive inhibitor of $:$ copper oxidase activity present.

\section{Discussion}

These results suggest that the functional abnormality in caeruloplasmin observed in these families is an inherited variant, which is not attributable to the presence of a serum inhibitor of copper oxidase. The $ᄋ$ individuals with this reduction of the oxidase activity $N$ of caeruloplasmin were all female, in whom the స్ట serum caeruloplasmin ranged from 11 to $36 \mathrm{mg} / \mathrm{dl}$, $\sigma$ but in five of the six subjects the values were either normal or near-normal. In all cases, including the two heterozygote mothers, the level of copper oxi- $\stackrel{\infty}{\rightarrow}$ dase activity was abnormally low and consistent with 7 that found in patients with Wilson's disease. Heterozygous carriers of Wilson's disease remain free of the $\underset{\mathbb{Q}}{\mathbb{D}}$ disease for life, even though about $20 \%$ exhibit a $\underset{\mathbb{D}}{\circ}$ low serum caeruloplasmin (Bickel et al., 1957;응 Sternlieb et al., 1961); in some series, however, 
caeruloplasmin has been estimated by the copper oxidase method and hence, on the basis of these observations, individuals may have been included in whom there were normal levels of caeruloplasmin despite the reduced oxidase activity.

Since the observation that the serum caeruloplasmin is usually low in Wilson's disease (Bearn and Kunkel, 1952; Scheinberg and Gitlin, 1952), distinct molecular species have been demonstrated which differ in chromatographic and electrophoretic behaviour (Curzon and Vallet, 1960; Broman, 1964). Morell and Scheinberg (1960) succeeded in separating four components of the compound in normal subjects and suggested the possibility of a qualitative defect in caeruloplasmin in Wilson's disease. Despite these observations the significance of this heterogeneity, remains obscure; moreover, it is now generally accepted that the low serum caeruloplasmin levels in Wilson's disease are not directly related to the retention of copper or the clinical manifestations. Similarly, with regard to the present report, deficient copper oxidase activity in caeruloplasmin appears to be unrelated to the aetiology or presentation of the disease since asymptomatic heterozygotes were also affected. The possibility exists that this variant may occur in the general population, and the fact that it was first observed in two families with Wilson's disease may be an artefact of ascertainment. However, the alternative suggestion that this caeruloplasmin variant may be associated with the 'Wilson's disease gene' provides additional evidence of genetic heterogeneity in Wilson's disease (Cox et al., 1972). In view of these findings it may be desirable to measure copper oxidase activity in parallel with caeruloplasmin during the investigation of suspected cases of Wilson's disease, especially where measurement of caeruloplasmin by the immunochemical method gives results within the normal range.

JLG and JS are supported by Fellowships from the Wellcome Trust. We gratefully acknowledge the helpful comments of Professor A. G. Bearn.

\section{References}

Bearn, A. G. (1953). Genetic and biochemical aspects of Wilson's disease. American Journal of Medicine, 15, 442449.

Bearn, A. G. and Kunkel, H. G. (1952). Biochemical abnormalities in Wilson's disease. Journal of Clinical Investigation, 31, 616. (Abstract).

Bickel, H., Neale, F. C., and Hall, G. (1957). A clinical and biochemical study of hepatolenticular degeneration (Wilson's disease). Quarterly Journal of Medicine, 26, 527558.

Broman, L. (1964). Chromatographic and magnetic studies on human ceruloplasmin. Acta Societatis Medicorum Upsaliensis, 69, Supplement 7, 1-85.

Cox, D. W., Fraser, F. C., and Sass-Kortsak, A. (1972). A genetic study of Wilson's disease: evidence for heterogeneity. American Journal of Human Genetics, 24, 646-666.

Curzon, G. and Vallet, L. (1960). The purification of human caeruloplasmin. Biochemical Journal, 74, 279-287.

Morell, A. G. and Scheinberg, I. H. (1960). Heterogeneity of human ceruloplasmin. Science, 131, 930-932.

Scheinberg, I. H. and Gitlin, D. (1952). Deficiency of ceruloplasmin in patients with hepatolenticular degeneration (Wilson's disease). Science, 116, 484-485.

Scheinberg, I. H. and Sternlieb, I. (1963). Wilson's disease and the concentration of caeruloplasmin in serum. Lancet, $1,1420-1421$.

Sternlieb, I., Morell, A. G., Bauer, C. D., Combes, B., de Bobes-Sternberg, S., and Scheinberg, I. H. (1961). Detection of the heterozygous carrier of the Wilson's disease gene. Journal of Clinical Investigation, 40, 707-715.

Sternlieb, I. and Scheinberg, I. H. (1968). Prevention of Wilson's disease in asymptomatic patients. New England Journal of Medicine, 278, 352-359. 